Página inicial: 574 - Página Final: 596

Tipo de artículo: Reflexión derivada de investigación

\title{
El fomento de las escuelas públicas en la Provincia de Antioquia en los primeros años de vida Republicana (1819-1828) Colombia
}

\author{
The Promotion of Public Schools in the Province of Antioquia in the Early Years \\ of the Republican Life (1819-1828) Colombia
}

\author{
Recibido: abril de 2017 Revisado: mayo de $2017 \quad$ Aceptado:junio de 2017
}

${ }^{1}$ Politólogo de la Universidad de Los Andes, Especialista en Gobierno Municipal, Especialista en Política Social y Magíster en Estudios Políticos de la Pontificia Universidad Javeriana, Miembro de Número de la Academia Colombiana de Historia, Director de la Biblioteca "Eduardo Santos" de la Academia Colombiana de Historia.

Contacto:

rogpitc@hotmail.com ORCID:

https://orcid.org/0000-0001$\underline{9937-0228}$
Por: Roger Pita Pico ${ }^{1}$

\begin{abstract}
Resumen
Durante los primeros años de vida republicana, el gobierno colombiano afrontó los retos de cobertura y financiación de las escuelas públicas de primeras letras en la provincia de Antioquia en medio de un ambiente social, económico y político adverso. Estos propósitos sucedieron en una etapa de transición en la cual era evidente el choque de mentalidades entre los principios pregonados por el antiguo régimen español y los principios liberales. Este proyecto se enmarcaba dentro de una apuesta política que tenía como objetivo cimentar las bases de una República y formar ciudadanos dispuestos a impulsar el progreso de esta región.
\end{abstract}

Palabras clave. Educación pública; escuelas; Antioquia; siglo XIX; República.

\begin{abstract}
During the first years of Republican life, the Colombian government faced the challenges of coverage and funding of public schools of first letters in the Province of Antioquia, in the midst of an adverse social, economic, and political environment. These purposes took place in a period of transition in which the clash of mentalities between the principles made by the former Spanish regime and liberal principles was evident. This project was framed within a political premise, which was intended to lay the foundations of a Republic and to form citizens willing to promote the progress of this region.
\end{abstract}

Key words: Public Education; Schools; Antioquia; XIX Century; Republic. 


\section{Introducción}

En la época colonial, muy poco interés brindó el gobierno español a las escuelas elementales. Algunas eran anexas a los colegios, pero la gran mayoría eran fundadas por conventos que ofrecían ese servicio educativo de manera gratuita. Existían también algunos planteles privados, especialmente dirigidos a formar los hijos de las familias más prominentes de la sociedad (Ahern, 1991, pp. 17-21).

La tensión política, el ambiente de guerra y el déficit fiscal que caracterizaron al periodo de Independencia que comenzó con el movimiento de emancipación política ocurrida en 1810, fueron elementos adversos que postergaron las posibilidades de impulso de la educación en estos territorios. Respecto a la economía, la nota predominante durante esta etapa revolucionara fue la situación de crisis en prácticamente todos los ámbitos.

De gran incidencia también fueron los cambios político-administrativos ocurridos durante los años de Independencia. Así entonces, durante el primer experimento de gobierno republicano (1810-1815) se dividió el territorio en Estados con algún grado de autonomía.

Un motivo de aliento durante este periodo de la Primera República Federativa fue el hecho de que la educación fue incluida en las primeras Cartas Constitucionales, llegándose incluso a dedicar una sección especial a esta temática, lo cual ratifica la importancia que tenía para los pioneros republicanos (Ocampo, 2012, pp. 81-95).

En 1812, los constituyentes de la provincia de Antioquia contemplaron el propósito de instalar escuelas gratuitas en todas las parroquias de su jurisdicción, pero confiriéndole al ente legislativo la responsabilidad de buscar medios de financiación sin gravar las rentas públicas (Constitución, 1812, pp. 65-66).

A partir de 1815 el territorio neogranadino quedó nuevamente bajo dominio español después de una apabullante campaña militar. Si bien durante esta fase de Reconquista se avanzó en materia de infraestructura, en realidad no se observaron esfuerzos en el fomento de la educación. Así las cosas, muy pocos fueron los progresos del sector durante estos años en comparación con la situación vivida antes del estallido revolucionario de 1810.

Después de la batalla de Boyacá del 7 de agosto de 1819 los republicanos allanaron el camino para el triunfo definitivo y, con ello, se abrió paso a una nueva organización. La Ley Fundamental de Colombia del 17 de diciembre de 1819 reunió en una sola República el territorio que comprendían la antigua Capitanía General de Venezuela y el virreinato de la Nueva Granada. La nueva República se dividió en tres departamentos: Venezuela, Quito y Cundinamarca, cada uno de ellos con su respectivo vicepresidente (Ley, 1819, p. 1).

Tan pronto ascendieron al poder, los republicanos formularon serias críticas al régimen español por el descuido en la política educativa, el atraso de la cultura y la ignorancia en que estaban sumidos buena parte de los neogranadinos. A esta desoladora situación se le sumaba la dudosa calidad de los maestros y la falta de conocimiento práctico y experimental (Ocampo, 1987, p. 22).

Los dirigentes de la temprana época republicana estuvieron muy empeñados en infundir en los sectores bajos y medios de la sociedad mayores destrezas laborales inculcando a través de la educación 
primaria y secundaria la disciplina por el trabajo, con lo cual se pretendía avanzar hacia el orden social y el progreso económico (Safford, 1989, p. 77).

Este artículo tiene por objeto analizar cómo durante los primeros años de vida republicana el gobierno afrontó los retos de cobertura y financiación de las escuelas públicas de primeras letras en la provincia de Antioquia en medio de un ambiente social, económico y político adverso. Estos propósitos sucedieron en una etapa de transición en la cual era evidente el choque de mentalidades entre los principios pregonados por el antiguo régimen español y los principios liberales. Este proyecto se enmarcaba dentro de una apuesta política que tenía como objetivo cimenatar las bases de una República y formar ciudadanos dispuestos a impulsar el progreso de una nación en ciernes.

\section{El marco legal}

El 6 de octubre de 1820 el vicepresidente Francisco de Paula Santander dictó un decreto que es considerado el primer plan de educación primaria en toda la República. Allí se reconoció que la instrucción pública era el medio más fácil para que los ciudadanos asimilaran sus derechos y deberes en sociedad, siendo responsabilidad del Estado asegurarles la educación para contribuir a su bienestar y felicidad. Los maestros debían enseñar a los niños a leer, escribir y contar, y además explicar los dogmas de la religión y de la moral cristiana. Con este decreto, el gobierno abrigaba la esperanza de que las ciencias, las artes, la agricultura y la industria progresarían a medida que el hábito de la lectura, de la escritura y de la aritmética se hicieran más comunes (Osorio, 1821, p. 46).

Este precedente normativo abrió el camino para nuevos impulsos a escala regional. Así por ejemplo, el 28 de febrero de 1821 el gobierno de Antioquia expidió un reglamento para la organización y economía de las escuelas de esta provincia (Martínez, 2011, pp. 394-400).

El 2 de agosto de este mismo año fue promulgada otra ley en donde quedó explícita la intención de dimensionar la escuela como "[...] la más generalmente difundida, pues era el origen sobre el cual se cimentaban los demás conocimientos humanos" (Actas, 1990, Vol. II, p. 157). Esta ley reiteró que los maestros debían enseñar los preceptos cristianos y los valores ciudadanos. Asimismo, el poder ejecutivo quedó autorizado para incentivar en las principales ciudades la creación de escuelas pilotos con el método lancasteriano, conocido también con el nombre de método de mutua instrucción, el cual consistía en que un solo maestro pudiera dirigir a un gran número de alumnos, contando con la colaboración directa de los estudiantes más aventajados en calidad de monitores para que de allí se fueran difundiendo este novedoso sistema de enseñanza a todas las provincias (Actas, 1990, Vol. II, p. 59).

Cabe anotar además que en la ley dictada el 20 de junio de este mismo año, mediante la cual se estableció la fundación de colegios públicos en las capitales de provincia, se dispuso que en estos planteles debía adecuarse una pieza para instalar allí una escuela lancasteriana (López, 1990, Vol. I, pp. 43-44).

Otra norma dictada por el general Santander el 26 de noviembre de 1821 estableció que, en aquellas ciudades, villas o parroquias en que se suprimieran conventos menores que tuviesen abiertas escuelas de primeras letras, éstas debían continuar funcionando con el religioso que estaba a cargo de ellas. El gobierno le asignaría a este preceptor una gratificación según su "mérito, aptitud y trabajo", recursos que saldrían de las rentas que antiguamente pertenecían a dichos conventos (Mier, 1983, t. 1, p. 10). 
Tan pronto asumieron el poder, los gobernantes republicanos dieron un gran impulso al establecimiento de escuelas lancasterianas aunque cabe aclarar que en algunos casos se optó también por suprimir escuelas del método antiguo para reemplazarlas por el nuevo sistema de enseñanza.

Un decreto promulgado el 26 de enero de 1822 dispuso que primero se fundaran escuelas normales del método lancasteriano en las ciudades de Bogotá y Caracas, y en Quito cuando estuviese liberada. Una vez desarrollada esta primera fase, serían expedidas órdenes a los intendentes de Cundinamarca, Boyacá, Magdalena, Cauca e Istmo de Panamá para que cada una de las provincias a su mando hiciera venir a Bogotá, con cargo a la renta de propios, un joven para que se instruyera en el nuevo método. Adquirida la capacitación y aprobado el respectivo examen, estos jóvenes debían regresar a sus provincias con el fin de convertirse en difusores del nuevo método a los maestros de las parroquias, quienes para el efecto debían viajar hasta la capital de cada provincia. En este caso la prioridad la tendrían las parroquias más cercanas y populosas. Durante ese tiempo de capacitación, los maestros de parroquia disfrutarían del sueldo que se les tenía asignados y, si esto no fuese suficiente, los padres de familia debían realizar una recolecta para asegurarles el hospedaje y la alimentación (El Eco de Antioquia, No. 2, 1822, p. 6).

El 3 de octubre de 1826 el vicepresidente Santander aprobó el denominado Plan de Estudios mediante el cual se dictaron algunas pautas sobre la estructura administrativa de las escuelas, el tipo de instrucción y el pago a maestros (Codificación, 1924, t. VII, p. 401).

En este nuevo marco normativo promulgado en la primera década de vida republicana, era claro ver cómo los gobernantes se mostraban menos empeñados en la religión, en la moralidad y en la salvación de la República, pues ahora el énfasis estaba dirigido al impulso del trabajo útil y del desarrollo económico (Safford, 1989, p. 80).

\section{El impulso a la cobertura}

En el antiguo régimen hispánico, el acceso a la educación era muy limitado y, de algún modo, reflejaba las desigualdades sociales y étnicas (Ahern, 1991, p. 21). Aunque la intención del gobierno republicano era transformar este desolador panorama a través de la masiva fundación escuelas en todas las poblaciones, en términos reales ese era un propósito difícil de alcanzar, especialmente en estos tiempos de posguerra en que apenas se adelantaban ingentes esfuerzos con miras a la recuperación económica.

Pese a todas las vicisitudes, las cifras en materia de cobertura educativa fueron ganando fuerza con el transcurrir de los años. Haciendo un balance general, el gobierno central reconoció en abril de 1823 que la ley del 2 de agosto de 1821 se había ejecutado hasta donde las circunstancias lo habían permitido. Así entonces, una multitud de escuelas se habían constituido pero se tenía la esperanza de que a nivel local y provincial se trabajara con mayor "constancia y asiduidad". A manera de comparación, se hizo énfasis en el estancamiento que padeció la educación durante los 300 años de régimen colonial mientras que ahora se mostraba una notable evolución en esparcir la enseñanza pública "aún en medio de los peligros de la guerra y del estruendo del cañón” (Restrepo, 1823, pp. 25-26).

Antioquia y otras provincias del área andina central, que por cierto habían sido las primeras en ser liberadas del poderío español, fueron las que marcaron el liderazgo en la difusión de la educación elemental. Progresivamente se fue introduciendo el método lancasteriano, más que todo en las 
ciudades de mayor importancia. La implementación de este tipo de escuelas implicó que algunos planteles del antiguo método se adaptaran al nuevo esquema educativo mientras que la mayoría siguió funcionando con el modelo tradicional hasta tanto hubiese la oportunidad de capacitar a los maestros y de conseguir la infraestructura necesaria.

En diciembre de 1821 se presentó un primer balance de las escuelas instaladas en Antioquia. Allí el gobierno provincial dio cuenta de haber trabajado activamente en la fundación de 50 planteles, la mayoría con recursos suficientes para el sostenimiento de los profesores (Correo, No. 125, 1821, p. 401).

Cáceres era una de las poblaciones en donde todavía no existían este tipo de establecimientos educativos debido a que fue el escenario de fuertes disputas entre patriotas y realistas. Aunque fue finalmente liberada por las fuerzas republicanas, muchos vecinos se hallaban huidos en los montes y la población estaba prácticamente arruinada (AGN, F. Instrucción Pública, t. 109, f. 305r).

A pesar de estos adelantos, algunos inconformismos salieron a la luz pública y los esfuerzos oficiales parecían no colmar todas las expectativas. Tal como lo expresó a mediados de 1822 un columnista en El Eco de Antioquia, eran varios los obstáculos que debía enfrentar el gobierno de esta provincia para la fundación y sostenimiento de estos centros educativos. Una prueba de ello era la urgencia de fundar en Medellín una nueva escuela "pagada por los pudientes", pues la existente no bastaba para brindar educación a los más de 200 niños de la villa. Desde las páginas de dicho medio impreso se instó a los padres de familia a sacrificar parte de sus fortunas en beneficio de la educación pública y a los eclesiásticos también se les invitó a ser solidarios con esta causa. De manera especial, se pidió a los editorialistas dedicar más espacio del semanario a promover las ventajas que ofrecía la educación pública y a crear conciencia sobre su importancia (El Eco de Antioquia, No. 10, 1822, p. 38). Al cabo de dos meses, se denunció en este mismo periódico cómo todavía se veían muchos párvulos ociosos en las calles, entretenidos en riñas de pollos, en tirar piedra o en jugar "chumbimbas" (El Eco de Antioquia, No. 18, 1822, p. 76).

El 22 de abril de este año el joven Víctor Gómez había viajado de Medellín a la ciudad de Bogotá con el fin de instruirse en el método lancasteriano (El Eco de Antioquia, No. 1, 1822, p. 3) y el 24 de enero de 1823 este maestro dio inicio a las clases en la nueva escuela inaugurada en Medellín. Precisamente por esos días se lanzó una convocatoria a los maestros de los cantones y parroquias de la provincia para que se hicieran presentes en aquella villa con el fin de aprender el método lancasteriano y así difundirlo en sus respectivas instituciones (El Eco de Antioquia, No. 35, 1823, p. 143). El 21 de abril de ese mismo año se abrió otra escuela de este tipo en la ciudad de Rionegro con abundancia de útiles escolares (AGN, F. Instrucción Pública, t. 107, ff. 622r, 629r).

Como se observa en el cuadro insertado a continuación, para 1823 se había logrado un alto nivel de cobertura en materia de educación primaria en el territorio de la provincia pues se hallaban instaladas escuelas en 51 poblaciones, de las cuales 7 correspondían a resguardos indígenas. 
Cuadro No. 1. Escuelas fundadas en la provincia de Antioquia en 1823

\begin{tabular}{|c|c|c|c|}
\hline Cantones & Lugares & Maestros & Fuentes de financiación \\
\hline \multirow{9}{*}{ Antioquia } & $\begin{array}{l}\text { Santa Fe de } \\
\text { Antioquia }\end{array}$ & Vacante & 300 pesos \\
\hline & San Jerónimo & Matías Lara & $\begin{array}{c}30 \text { pesos de la renta de } \\
\text { propios y } 170 \text { pesos de la } \\
\text { contribución de los vecinos }\end{array}$ \\
\hline & Sacaojal & $\begin{array}{l}\text { Manuel María } \\
\quad \text { Lara }\end{array}$ & $\begin{array}{c}80 \text { pesos de la renta de } \\
\text { propios y } 120 \text { pesos de la } \\
\text { contribución de los vecinos }\end{array}$ \\
\hline & Urrao & Vacante & $\begin{array}{l}200 \text { pesos de la contribución } \\
\text { de los vecinos }\end{array}$ \\
\hline & San Andrés & - & $\begin{array}{l}120 \text { pesos de la contribución } \\
\text { de los vecinos }\end{array}$ \\
\hline & Buriticá* & $\begin{array}{r}\text { Francisco } \\
\text { Javier García }\end{array}$ & $\begin{array}{l}120 \text { pesos de la contribución } \\
\text { de los vecinos }\end{array}$ \\
\hline & Sabanalarga & Blas Leal & $\begin{array}{l}120 \text { pesos de la contribución } \\
\text { de los vecinos }\end{array}$ \\
\hline & Cañasgordas* & Lope Gallego & $\begin{array}{l}120 \text { pesos de la contribución } \\
\text { de los vecinos }\end{array}$ \\
\hline & Sopetrán* & $\begin{array}{l}\text { Carmelo } \\
\text { Tabares }\end{array}$ & $\begin{array}{c}140 \text { pesos de la contribución } \\
\text { de los vecinos y } 100 \text { pesos de los } \\
\text { sobrantes de las tierras de } \\
\text { resguardos }\end{array}$ \\
\hline \multirow{11}{*}{ Medellín } & Medellín & Víctor Gómez & $\begin{array}{l}430 \text { pesos de dotaciones } \\
\text { particulares }\end{array}$ \\
\hline & Amagá & $\begin{array}{l}\text { José Antonio } \\
\text { Restrepo }\end{array}$ & $\begin{array}{c}240 \text { pesos de la contribución } \\
\text { de los vecinos }\end{array}$ \\
\hline & Titiribí & Isidoro Talero & $\begin{array}{l}240 \text { pesos de la contribución } \\
\text { de los vecinos }\end{array}$ \\
\hline & Envigado & $\begin{array}{l}\text { José María } \\
\text { Escobar }\end{array}$ & $\begin{array}{l}240 \text { pesos de la contribución } \\
\text { de los vecinos }\end{array}$ \\
\hline & Barbosa & $\begin{array}{r}\text { Vicente } \\
\text { Rodríguez }\end{array}$ & $\begin{array}{l}198 \text { pesos de la contribución } \\
\text { de los vecinos }\end{array}$ \\
\hline & Copacabana & $\begin{array}{l}\text { Joaquín } \\
\text { Jaramillo }\end{array}$ & $\begin{array}{c}198 \text { pesos de la contribución } \\
\text { de los vecinos }\end{array}$ \\
\hline & Hatoviejo & Francisco Villa & $\begin{array}{l}198 \text { pesos de la contribución } \\
\text { de los vecinos }\end{array}$ \\
\hline & San Cristóbal & Vacante & $\begin{array}{c}144 \text { pesos de la contribución } \\
\text { de los vecinos }\end{array}$ \\
\hline & Belén & Vacante & $\begin{array}{l}200 \text { pesos de la contribución } \\
\text { de los vecinos }\end{array}$ \\
\hline & Iguanacita & Vacante & $\begin{array}{l}96 \text { pesos de la contribución de } \\
\text { los vecinos }\end{array}$ \\
\hline & Guayabal & - & $\begin{array}{c}200 \text { pesos de la contribución } \\
\text { de los vecinos }\end{array}$ \\
\hline
\end{tabular}




\begin{tabular}{|c|c|c|c|}
\hline & La Estrella* & $\begin{array}{l}\text { Juan de Dios } \\
\text { Rodríguez }\end{array}$ & $\begin{array}{c}120 \text { pesos de la contribución } \\
\text { de los vecinos }\end{array}$ \\
\hline \multirow{13}{*}{ Rionegro } & Rionegro & $\begin{array}{c}\text { Manuel } \\
\text { Antonio Balcázar }\end{array}$ & $\begin{array}{l}140 \text { pesos de la renta de } \\
\text { propios y } 160 \text { pesos de la } \\
\text { contribución de los vecinos }\end{array}$ \\
\hline & Guarne & Andrés Tobón & $\begin{array}{l}200 \text { pesos de la contribución } \\
\text { de los vecinos }\end{array}$ \\
\hline & San Vicente & Rafael Duque & $\begin{array}{c}200 \text { pesos de la contribución } \\
\text { de los vecinos }\end{array}$ \\
\hline & Sonsón & $\begin{array}{l}\text { Juan de Dios } \\
\text { Ramírez }\end{array}$ & $\begin{array}{l}200 \text { pesos de la contribución } \\
\text { de los vecinos }\end{array}$ \\
\hline & Abejorral & Gabriel Arango & $\begin{array}{l}200 \text { pesos de la contribución } \\
\text { de los vecinos }\end{array}$ \\
\hline & El Retiro & $\begin{array}{l}\text { Eugenio } \\
\text { Vallejo }\end{array}$ & $\begin{array}{l}200 \text { pesos de la contribución } \\
\text { de los vecinos }\end{array}$ \\
\hline & Concepción & $\begin{array}{l}\text { Salvador } \\
\text { Osorio }\end{array}$ & $\begin{array}{l}139 \text { pesos de la contribución } \\
\text { de los vecinos }\end{array}$ \\
\hline & $\begin{array}{r}\text { Santo } \\
\text { Domingo } \\
\end{array}$ & $\begin{array}{l}\text { Francisco } \\
\text { Gaviria }\end{array}$ & $\begin{array}{c}120 \text { pesos de la contribución } \\
\text { de los vecinos }\end{array}$ \\
\hline & $\begin{array}{r}\text { Santa } \\
\text { Bárbara }\end{array}$ & - & $\begin{array}{l}96 \text { pesos de la contribución de } \\
\text { los vecinos }\end{array}$ \\
\hline & Aguadas & Bruno Restrepo & $\begin{array}{l}96 \text { pesos de la contribución de } \\
\text { los vecinos }\end{array}$ \\
\hline & Chapa & Vicente Osorio & $\begin{array}{l}96 \text { pesos de la contribución de } \\
\text { los vecinos }\end{array}$ \\
\hline & Pereira* & Silverio Álvarez & $\begin{array}{l}114 \text { pesos de la contribución } \\
\text { de los vecinos }\end{array}$ \\
\hline & Zabaletas* & Gabino Soto & - \\
\hline \multirow{7}{*}{ Marinilla } & Marinilla & $\begin{array}{l}\text { Salvador } \\
\text { Gómez }\end{array}$ & $\begin{array}{c}144 \text { pesos de la renta de } \\
\text { propios y } 96 \text { pesos de la } \\
\text { contribución de los vecinos }\end{array}$ \\
\hline & San Carlos & - & $\begin{array}{l}96 \text { pesos de la contribución de } \\
\text { los vecinos }\end{array}$ \\
\hline & El Santuario & Ramón Gómez & $\begin{array}{c}200 \text { pesos de la contribución } \\
\text { de los vecinos }\end{array}$ \\
\hline & La Ceja & Bautista Mejía & $\begin{array}{l}200 \text { pesos de la contribución } \\
\text { de los vecinos }\end{array}$ \\
\hline & El Carmen & $\begin{array}{c}\text { Juan } \\
\text { Nepomuceno } \\
\text { Betancur } \\
\end{array}$ & $\begin{array}{c}144 \text { pesos de la contribución } \\
\text { de los vecinos }\end{array}$ \\
\hline & Los Baos & Joaquín Duque & $\begin{array}{l}109 \text { pesos de la contribución } \\
\text { de los vecinos }\end{array}$ \\
\hline & Peñol* & $\begin{array}{l}\text { Buenaventura } \\
\text { Pérez }\end{array}$ & $\begin{array}{l}60 \text { pesos de los sobrantes de } \\
\text { las tierras de resguardos }\end{array}$ \\
\hline Nordeste & Remedios & $\begin{array}{c}\text { Juan } \\
\text { Nepomuceno } \\
\text { Cano }\end{array}$ & $\begin{array}{l}96 \text { pesos de la contribución de } \\
\text { los vecinos }\end{array}$ \\
\hline
\end{tabular}




\begin{tabular}{|c|c|c|c|}
\hline & $\begin{array}{c}\text { San } \\
\text { Bartolomé }\end{array}$ & Lucas __ & $\begin{array}{c}50 \text { pesos de la contribución de } \\
\text { los vecinos }\end{array}$ \\
\hline & Zaragoza & Blas Segovia & 110 pesos \\
\hline & Yolombó & Vacante & 90 pesos \\
\hline & Cancán & Andrés & 100 pesos \\
\hline \multirow{5}{*}{$\begin{array}{l}\text { Valle de } \\
\text { Osos }\end{array}$} & Santa Rosa & Eloy de Hoyos & $\begin{array}{c}240 \text { pesos de la contribución } \\
\text { de los vecinos }\end{array}$ \\
\hline & Yarumal & $\begin{array}{l}\text { José Antonio } \\
\text { Soto }\end{array}$ & $\begin{array}{c}240 \text { pesos de la contribución } \\
\text { de los vecinos }\end{array}$ \\
\hline & Carolina & $\begin{array}{l}\text { Juan Antonio } \\
\text { Ortega }\end{array}$ & $\begin{array}{l}240 \text { pesos de la contribución } \\
\text { de los vecinos }\end{array}$ \\
\hline & San Pedro & $\begin{array}{l}\text { Miguel } \\
\text { Moncada }\end{array}$ & $\begin{array}{c}240 \text { pesos de la contribución } \\
\text { de los vecinos }\end{array}$ \\
\hline & Don Matías & $\begin{array}{r}\text { Diego } \\
\text { Echeverri }\end{array}$ & $\begin{array}{l}144 \text { pesos de la contribución } \\
\text { de los vecinos }\end{array}$ \\
\hline
\end{tabular}

Fuente: AGN, F. Instrucción Pública, t. 108, f. 381v; AGN, F. Instrucción Pública, t. 107, f. 629r.* Resguardos indígenas

En febrero de 1827 los gobernantes de la provincia recopilaron nuevas estadísticas sobre el nivel de cobertura (Ver Cuadro No. 2). Allí se observa que los cantones de Medellín y Rionegro eran que los que aglutinaban el mayor número de educandos.

Cuadro No. 2. Número de estudiantes en los cantones de la provincia de A
\begin{tabular}{|c|c|}
\hline Cantones & No. estudiantes \\
\hline Medellín & 356 \\
\hline Rionegro & 401 \\
\hline Santa Fe de Antioquia & 132 \\
\hline Marinilla & 107 \\
\hline Santa Rosa & 20 \\
\hline Total & 1.016 \\
\hline
\end{tabular}

Fuente: AGN, F. Instrucción Pública, t. 107, f. 656r.

La desidia de los funcionarios públicos, la desconfianza frente al método lancasteriano, la indiferencia de los padres, la falta de una acción oficial coordinada y la escasez de recursos, fueron factores que obstaculizaron el proceso de apertura de escuelas en algunos puntos de la provincia.

En uno de sus informes de gobierno presentados al Congreso de la República, el vicepresidente Santander reconoció que en los primeros años de vida republicana se había incrementado el número de escuelas, pero para obtener avances sustanciales era necesario esperar algún tiempo pues los pueblos no podían responder con tantas contribuciones ni tampoco se conseguían los maestros suficientes para cumplir con todas las expectativas.

A medida que fue cediendo el estruendo de la guerra, se hizo más propicio el ambiente para lograr un mayor cubrimiento educativo. A juzgar por las estadísticas manejadas por el gobierno, para el mes de noviembre de 1825 existían escuelas en prácticamente todas las provincias de la República (Restrepo, 1826, p. 17).

En el Plan de Estudios, dictado por el general Santander por decreto del 30 de octubre de 1826, se fijaron unas metas muy precisas en materia de cobertura de las escuelas lancasterianas. Así entonces, 
para el 19 de abril de 1827 debían estar instaladas estas escuelas en todas las capitales de provincia, el 20 de julio en todas las cabeceras de cantón y para el 25 de diciembre en todas las parroquias de la República. Una vez alcanzado este propósito, no sería permitido el funcionamiento de planteles con el "antiguo vicioso método" (Codificación, 1924, t. VII, p. 402). No obstante, estas eran unas metas realmente ambiciosas que no se cumplieron a cabalidad pues el ritmo de fundación de las escuelas del nuevo método iba a paso lento, especialmente en las pequeñas y remotas parroquias.

Según datos suministrados a nivel oficial, a mediados de 1827 existían en Colombia 52 escuelas lancasterianas con 3.509 niños y 434 planteles del método antiguo con 16.200 estudiantes. En todas las provincias de la República había por lo menos una o dos escuelas con el nuevo modelo de enseñanza. Así las cosas, para esta fecha faltaba mucho trecho para lograr una uniformidad en el método que era uno de los anhelos principales del gobierno republicano.

\section{El reto de asistir a clase}

Un tema de hondas implicaciones en materia de cobertura era la idea que se había planteado de comprometer a los padres de enviar sus hijos a la escuela. Sin embargo, seguían persistiendo en los progenitores algunas reservas que obstaculizaban el feliz cumplimiento de ese propósito y eso se vio reflejado en el hecho de que no pocos se mostraron reacios a contribuir económicamente con el sostenimiento del plantel educativo.

La situación de guerra que se vivió en el periodo de Independencia terminó influyendo notoriamente en el nivel de asistencia académica. Sobre esto ya existía un claro antecedente en los tiempos de la Primera República Federativa cuando el gobierno provincial de Antioquia, en medio de un ambiente cargado de tensión política interna y externa, dictó un decreto a finales de 1814, en el cual se ordenaba formar militarmente a los alumnos de las escuelas de primeras letras para cultivarles el amor al ejercicio de las armas desde la niñez "como un deber natural de todo ciudadano" (Gazeta No. 11, 1814, p. 43).

El decreto dictado el 6 de octubre de 1820 por el vicepresidente Santander mandó a los jueces a elaborar un padrón de los niños entre los 4 y 12 años de edad, obligando a los padres a enviarlos a las aulas. Los gobernadores políticos de cada provincia adoptarían severas represalias contra aquellos renuentes a acatar la anterior orden. Esto no era óbice para que los progenitores enviaran sus hijos a las escuelas de la capital de provincia o a otra que consideraran más conveniente pero debían reportar oportunamente esta decisión a los jueces (Osorio, 1969, p. 154).

En el debate promovido meses más tarde al interior del Congreso de Cúcuta, el parlamentario José Manuel Restrepo creía que cualquier tipo de medida impositiva coartaba el derecho a la libertad. Una opinión contraria fue esbozada por Antonio María Briceño, quien pensaba que a los padres les asistía el deber de dar a conocer a sus hijos los derechos ciudadanos y para ello era indispensable que estos aprendieran a leer. Así entonces, Briceño era partidario de que las multas quedaran a discreción de los jueces, quienes en últimas debían evaluar si existían o no causas justas para penalizar a los padres.

Por su parte, el diputado Vicente Azuero creía que debía trazarse una distinción entre los habitantes de los poblados y los que vivían dispersos en los campos, pues no siempre estos gozaban de los recursos suficientes para enviar y mantener a sus hijos en aquellas cabeceras urbanas. Otra razón económica de peso adicionó el congresista Nicolás Ballén de Guzmán a esta discusión tras considerar 
que no tenía sentido presionar a los padres cuando estos apenas tuviesen un hijo como único jornalero de la casa, cuyo trabajo se demostrara que era vital para la subsistencia del núcleo familiar.

Luego de ser sopesados estos criterios, en el texto final de la ley del 2 de agosto de 1821 se resolvió que, siendo una prioridad el que todos los pequeños aprendieran los principios básicos del saber, los jueces debían formar un padrón en el que quedaran registrados todos los niños de 6 a 12 años de edad. Adicionalmente, se hizo un llamado especial a los padres que no se hubiesen decidido aún a remitir sus hijos a la escuela en el término de un mes después de cumplida la edad necesaria o de haberse constituido este centro educativo. Los omisos incurrirían en una multa de cuatro pesos que sería doblada y aplicada para el fondo de la misma escuela si en el plazo adicional de 15 días no atendían el requerimiento. Únicamente serían exceptuados aquellos vecinos en estado de pobreza que viviesen distantes del pueblo. De todos modos, estas medidas de carácter coercitivo no eran impedimento para que los padres brindaran a sus hijos una instrucción privada o para que los inscribieran en el plantel de su preferencia (Actas, 1990, Vol. II, pp. 56-159).

En una carta enviada y publicada a principios de septiembre de 1822 en la prensa de la provincia de Antioquia, se cuestionó el hecho de que hasta qué punto se había cumplido la mencionada norma que ordenaba efectuar un padrón de los niños para obligar a sus padres a matricularlos en las escuelas. El corresponsal pidió encarecidamente a los editores del periódico responder a esta inquietud o de lo contrario transmitírsela a las instancias oficiales responsables de este tema con el fin de que implementaran las medidas convenientes para subsanar esa problemática (El Eco de Antioquia, No. 16, 1822, p. 67).

\section{Educación y celebraciones públicas}

Durante estos primeros años de vida republicana, se realizaron celebraciones de apertura de planteles educativos y certámenes escolares de carácter público, eventos que, aún cuando a primera vista eran de índole estrictamente académico, de todas maneras, estaban cargados de un gran significado político pues exhibían muchos de los rasgos distintivos de las celebraciones políticas desarrolladas durante esa misma época (Pita, 2016).

En las temáticas y contenidos de los ejercicios académicos, en los discursos y en las arengas estaba siempre presente el honor a la Patria. En este contexto, el sector educativo era concebido como un medio eficaz y expedito para alcanzar el progreso y la felicidad dentro del proceso de consolidación de la República (Osorio, 1969, p. 154).

Dentro de la programación de las ceremonias educativas fue frecuente traer a colación y alabar aquellas máximas figuras políticas y militares de la naciente época republicana, principalmente al presidente Simón Bolívar y al vicepresidente Francisco de Paula Santander por su tesonera labor de fomento en favor de la educación pública, además de otros destacados próceres y oficiales de batalla. En cierto modo, el propósito con estas celebraciones era legitimar políticamente las nuevas autoridades. Las ceremonias fueron asimismo una ocasión propicia para rendir homenaje a aquellos funcionarios y benefactores, cuya influencia había sido decisiva en el establecimiento y adelanto de los planteles educativos.

El 24 de enero de 1823 abrió sus puertas en la villa de Medellín la escuela lancasteriana ubicada al interior de las instalaciones del colegio de Antioquia. La celebración transcurrió en medio de la música 
militar y del desfile de los escolares. Asistieron los magistrados, los jueces, los padres de familia y varias damas que "ennoblecieron y adornaron con su presencia la sala, dándole mayor lucimiento al acto". El aula de la escuela se hallaba situada en la parte baja e interior del colegio y medía 25 varas de longitud y 9 de latitud. La dotación estrenada ese día constaba de 18 mesas con sus respectivos bancos, 18 semicírculos para practicar lectura, 68 pizarras, 68 lapiceros, 68 lápices, 58 silabarios y un buen número de cartillas elementales para aprender a leer, escribir y contar. Un total de 30 escudos fueron elaborados especialmente por las damas de la villa para incentivar a los monitores y a los niños que sobresalieran por su aplicación y adelantamiento (El Eco de Antioquia, No. 35, 1823, p. 143; El Eco de Antioquia, No. 36, 1823, p. 148).

A las palabras de bienvenida del gobernador de la provincia, le siguió un discurso pronunciado por el preceptor con un emotivo tono político. Inmediatamente después los niños pusieron en práctica el nuevo método que venía inculcándose desde hacía apenas veinte días. Concluido el evento, los alumnos salieron formados en medio de la música hasta la plaza mayor en donde lanzaron vítores al presidente Simón Bolívar, al vicepresidente Santander y al gobernador de la provincia. El pueblo, entre tanto, se mostró muy complacido con la nueva opción de progreso educativo para la villa.

El espíritu de celebración pública cobijó también a las actividades académicas. Ya sobre este tema se había legislado durante la primera fase republicana. Aunque muchas de las materias a evaluar en estos certámenes eran prácticamente las mismas que se dictaban en tiempos del antiguo régimen español, ahora emergían nuevas temáticas con un hondo significado político, imbuidas bajo los nuevos aires de modernidad, alusivas al régimen republicano recién implantado y al proceso de construcción de nación.

En el reglamento para las escuelas fijado en 1819 por el gobierno de la provincia de Antioquia se dispuso que a finales de noviembre o principios de diciembre todos los escolares debían presentar públicamente un examen, acto al cual asistiría el cabildo y algunos vecinos en calidad de examinadores. El objetivo primordial era "hacer relucir el mérito de los de mayor talento y aplicación" (Martínez, 2011, pp. 377-378).

Desde esta provincia se reportó al gobierno central una intensa programación en materia de certámenes. En el numeral 17 del reglamento expedido el 28 de febrero de 1821 por el gobernador José Manuel Restrepo, se introdujeron nuevos detalles sobre el procedimiento que debía seguirse durante los eventos académicos desarrollados en esta zona:

Los curas presidirán también como delegados del Gobierno los certámenes que los escolares deben tener cada cuatro meses. Se verificarán en la primera semana de los meses de enero, mayo y septiembre. El maestro nombrará los niños de cada clase que deben responder a las preguntas que les hagan los demás de la misma clase, y las materias que cada uno ha de sostener. El cura, los jueces y otros asistentes que se convidarán al acto, podrán preguntar para que luzcan los conocimientos de los niños (AGN, F. Instrucción Pública, t. 107, ff. 614A-614F).

Entre tanto, el cura y los jueces debían motivar a los vecinos interesados en el aprovechamiento de sus hijos, para que en cada certamen se recogieran uno o dos premios que serían adjudicados al alumno de mayor rendimiento académico. Se aclaró que este gesto solidario se mantendría hasta que el gobierno contara con fondos propios para asignar dichos premios. 
Con base en estos parámetros, la parroquia de Sopetrán organizó el 7 de junio un certamen académico. Reunidos previamente los vecinos más notables, en compañía del juez indio y del cura José Ignacio Cardona se dirigieron luego a la casa de la escuela en medio de repiques de campanas y cohetes. El maestro seleccionó 12 pequeños, entre quienes figuraban 2 indios, con el fin de examinarlos en temas de religión, moral cristiana, aritmética, escritura y derechos del hombre. El niño Zacarías Sevillano lanzó una arenga ante la nutrida audiencia que "absorta admiraba" la viveza de los educandos. El gobernador Andrés de Uruburu felicitó a los promotores de este acto académico e instó a los vecinos para que en las próximas ocasiones se recogiera alguna cantidad de dinero que sirviera para premiar a los alumnos más adelantados (AHA, F. Gobernación de Antioquia, t. 122, ff. 46r-47r).

A los estudiantes más sobresalientes del certamen realizado en el mes de noviembre en la escuela de la población de Remedios se les gratificó no con dinero sino simbólicamente con grados militares: a Francisco Gálvez se le premió como capitán de la compañía, a Crispín Argüelles como teniente, a Francisco Álamo como alférez, a Zoilo Pérez como sargento y a Casimiro Páez como cabo. Los organizadores de este acto abrigaban la esperanza de que estos premios serían un estímulo para obtener mayores progresos en los próximos certámenes (AHA, F. Gobernación de Antioquia, t. 122, f. 167r).

La escuela de la ciudad de Santa Fe de Antioquia, capital de la provincia, realizó en el mes de septiembre de 1822 su tercer certamen académico en donde más de 30 niños fueron sondeados en temas de religión, derechos del hombre, derechos del ciudadano, formas de gobierno, división territorial de Colombia, aritmética y números romanos. Toribio Arrubla, uno de los escolares más aventajados, pronunció un discurso alegórico al evento. Marcelino Parias, Segundo Martínez, Feliciano Tirado, Rafael González, Pedro Ortiz, Francisco Campillo, Ildefonso y Pedro Pastor, descollaron por su nivel de aprovechamiento académico. Los excelentes resultados obtenidos fueron atribuidos al esmero y dedicación del preceptor Antonio Balcázar (El Eco de Antioquia, No. 19, 1822, p. 77).

En 1825 los discípulos de la escuela de primeras letras de la ciudad de Rionegro presentaron examen de religión, gramática castellana, aritmética, fundamentos del gobierno de Colombia, derechos del hombre, deberes del ciudadano, reglas de urbanidad, buena crianza y máximas morales, políticas y republicanas. Asimismo, dieron varias definiciones sobre la moneda, las medidas y el tiempo (Gaceta, No. 198, 1825, p. 2).

\section{El reto de la financiación}

Los embargos, los saqueos, las contribuciones forzosas, los donativos y la ruina provocada por la confrontación militar en el proceso de Independencia, eran factores que habían tenido un impacto generalizado en la economía neogranadina.

Es por ello que las fuentes de financiación de la educación pública fue uno de los temas más álgidos de discusión durante la naciente República. Varias opciones de recursos públicos, privados y mixtos fueron analizadas al interior del gobierno y del Congreso ante el déficit de las arcas públicas, los crecidos gastos destinados a la seguridad militar y el estado de desaceleración económica.

El decreto del 6 de octubre de 1820 fue el que trazó a nivel nacional los lineamientos básicos para el proceso de financiación de la educación elemental. Allí se ordenó que las ciudades y villas con rentas de propios debían establecer una escuela pública. Para tal efecto, los gobernadores políticos obligarían 
a los cabildos para que "inmediatamente y sin excusa" procedieran a realizar esta fundación. Además de esto, era deber de cada convento de religiosos, excepto el de San Juan de Dios, instalar una escuela.

Aquellas parroquias con más de treinta vecinos, debían también fundar escuela pública pero costeada por ellos mismos. El juez político o comandante militar de cada localidad tenía el compromiso de concientizarlos de la importancia de este propósito y de comprometerlos a sufragar mensualmente una cantidad proporcional a las posibilidades económicas de cada uno, cuya suma total no podía exceder de 300 pesos ni ser inferior a 200. Todos los propietarios estaban obligados al aporte, así no vivieran en sus domicilios. En los pueblos pequeños con menos de treinta vecinos, a los padres se les abrió la opción de mandar a sus hijos a las escuelas de las ciudades más próximas (Osorio, 1969, p. 154).

En razón a las dificultades que algunos lugares de la provincia de Antioquia tenían en cumplir con la meta de pagar a los maestros los 200 pesos fijados por la ley, el gobernador político José Manuel Restrepo decidió mediante decreto del 31 de enero de 1821 fijar una categorización de escuelas según el nivel de prosperidad de cada población. Así entonces, se establecieron las escuelas de primer orden con un sueldo para los maestros de 200 a 300 pesos. En aquellas parroquias con escasos recursos se establecieron las escuelas de segundo orden, pudiéndose en estos casos pagar a los maestros por debajo de 200 pesos. Esta clasificación contó con la plena comprensión y aquiescencia del gobierno central (AGN, F. Instrucción Pública, t. 107, f. 616r).

En el mes de mayo, Restrepo dio a conocer al secretario del Interior las dificultades que había para fundar escuelas en los lugares de corta población y escasos recursos, razón por la cual propuso que en estos sitios se aplazara la creación de escuelas hasta tanto no se lograran allí las condiciones económicas y el crecimiento demográfico que permitiesen sostener dicho establecimiento educativo (AGN, F. Instrucción Pública, t. 107, f. 611r).

Posteriormente, la ley del 2 de agosto de 1821 decidió que en todas las ciudades, villas y parroquias de más de 100 vecinos debía haber por lo menos una escuela de primeras letras. Las ciudades y villas sufragarían los gastos de dotación con los recursos de las rentas de propios, pero allí donde estos recursos fueren insuficientes y, en las parroquias, había que recurrir a la solidaridad de los vecinos, comprometiéndose voluntariamente a efectuar los pagos mensuales. Si de este modo no se cubría la cantidad requerida para la escuela, las autoridades locales se encargarían de hacer un repartimiento “justo y moderado" teniendo en cuenta el patrimonio y número de hijos de cada vecino cabeza de familia. Esta lista cobijaba a los solteros y exceptuaba a los pobres, cuyos hijos accederían gratuitamente a la educación. Era también deber de los vecinos conseguir la sede para la escuela y los útiles indispensables para el trabajo académico.

Cabe precisar que los gastos para el establecimiento de las escuelas lancasterianas eran muy superiores en comparación con los planteles del antiguo método. Para las primeras existían una serie de requisitos estipulados en el manual, considerados como indispensables para la aplicación del nuevo método de enseñanza: especificaciones en el tamaño y forma del salón de clases, bancos y mesas diseñadas especialmente, rueda del alfabeto, telégrafos (tablitas de 6 pulgadas de largo y 4 de ancho utilizadas para registrar el número de la clase), gavetas para lápices, tablas de lecturas, distintivos de clase, punteros, campanillas, silbatos y reloj (Manual, 1826, p. 112). 
Cuando aún estaba viva la discusión sobre las fórmulas de financiamiento de las escuelas, una nueva alternativa surgió a raíz de la ley del 28 de julio expedida este mismo año en la cual se dispuso que los fondos, bienes y edificios de los conventos suprimidos fueran invertidos en la educación pública. Este marco normativo abrió paso para que el vicepresidente Santander dictara una serie de decretos que autorizaban la instalación de escuelas y colegios públicos en diferentes poblaciones de la República.

Ante la crisis fiscal imperante, los impuestos fueron fuentes de recursos de gran apoyo para el desarrollo de la educación básica. En la ciudad de Santa Fe de Antioquia se había establecido en 1821 un impuesto de 4 pesos por cada res sacrificada para el normal abasto de carne en esta localidad, cuyos recaudos se destinaban para la construcción de una nueva sede para la sala capitular. Una vez concluida esta edificación, el cabildo propuso a principios del año siguiente que se utilizaran esos recaudos para un nuevo propósito de carácter público: el pago de maestro y la dotación de útiles. Con esta medida se pretendía evitar exigirle al vecindario una exacción directa.

El gobernador José Manuel Restrepo aprobó esta propuesta, pero con la condición de que, cuando fueran insuficientes estos recursos, el vecindario debía responder por el faltante. Entre tanto, el cabildo de la ciudad aceptó ceder "gustosamente en obsequio de tan loable objeto" (AGN, F. Instrucción Pública, t. 107, f. 588r; AHA, F. Gobernación de Antioquia, t. 122, f. 7r).

Otra opción altamente estimada por el gobierno fueron las donaciones, las cuales fueron además una muestra de la solidaridad en procura de la causa de la educación pública. Sin embargo, cabe aclarar que no fue precisamente el espíritu espontáneo de cooperación el motivo central que impulsó siempre a realizar este tipo de contribuciones pues, en la práctica, pudo existir la amenaza de ser señalado por las autoridades como indiferente frente a los proyectos estatales educativos o también pudo influir el interés particular por lograr alguna prerrogativa o beneficio a cambio de la donación.

Sea cual fuera el monto de la donación o el origen del donante, lo que realmente vale destacar es el sacrificio que este auxilio significaba en momentos cruciales en que la región apenas se recuperaba de una prolongada crisis económica generada por las guerras de Independencia, época en la que fueron frecuentes los saqueos, los donativos forzosos, los embargos y el deterioro de los capitales privados.

Los habitantes de la parroquia de Sopetrán fueron convocados en febrero de 1821 para contribuir al pago del maestro de la escuela. Al final concurrieron 212 contribuyentes que reunieron la suma total de 140 pesos con aportes que oscilaban entre 4 reales y 4 pesos, siendo la cuota más alta la del cura Gregorio Robledo (AHA, F. Gobernación de Antioquia, t. 122, f. 41r).

En el mes de septiembre, en Medellín las autoridades solicitaron al vecindario un aporte a manera de préstamo para el sostenimiento de la escuela del método antiguo que existía en esa villa, dineros que serían reintegrados por la renta de propios. El llamado se hizo en principio a los padres que tenían hijos en este plantel. Al final, se recaudaron 129 pesos, una cifra ínfima para las expectativas de las autoridades que no dudaron en criticar lo que ellos denominaron "pretextos frívolos" expuestos por algunos ciudadanos para escabullirse de esta contribución.

Juan Bautista Ángel, por ejemplo, exigió ver la orden oficial que autorizaba dicha recolecta. Don Pedro Callejas se mostró en disposición de colaborar siempre y cuando los otros vecinos se sumaran a este proyecto educativo. Don José Antonio Jiménez entregó su aporte pero criticó el hecho de que por esos días la escuela se hallaba cerrada. Las viudas Rafaela Vélez y Francisca Piedrahita 
argumentaron estar ilíquidas debido a que aún no podían disponer de los capitales de sus difuntos maridos. Evaristo Pinillos, por su parte, aportó 12 pesos, pero supeditado a que se cumpliera la promesa de reintegro de estos dineros. Antes de ofrecer su contribución, Luis Torres quería conocer el balance actualizado de las cuentas de la renta de propios para corroborar el estado de escasez de los recursos oficiales, comprometiéndose a pagar a pesar de que su hijo no sería beneficiario pues ya recibía clases privadas en su casa. El pretexto esgrimido por José Antonio Callejas para no aportar era porque su padre había donado tiempo atrás un total de 800 pesos para la causa de la educación pública. Por su lado, Francisco Estrada y la esposa de Vicente Fernández reconocieron haber entregado 10 pesos cada uno al anterior alcalde para el mismo propósito, pero ahora les resultaba muy difícil responder con la cuota exigida. Pedro Hernández y el presbítero José Antonio Palacios aseguraban simplemente no tener con qué responder pues ni siquiera tenían cómo sostenerse.

Al parecer, ante la escasa respuesta inicial fue necesario extender la convocatoria a todos los vecinos pudientes de la ciudad, situación que suscitó cierto inconformismo como el expresado por los ciudadanos José María Uribe y Francisco Vélez, quienes se escudaron en el hecho de que ellos no tenían hijos y por tanto no estaban sujetos a la directriz del gobierno local (AGN, F. Instrucción Pública, t. 107, ff. 607r-610v).

En 1822 el gobierno provincial convocó con éxito a funcionarios, a vecinos y al estamento eclesiástico para arreglar la sede del colegio en donde sería instalada la escuela lancasteriana (El Eco de Antioquia, No. 21, 1822, p. 88). Semanas atrás, se habían logrado recoger algunos recursos, producto de los réditos de los préstamos que algunos prestantes ciudadanos de Medellín habían hecho al gobierno en los tiempos de la revolución (El Eco de Antioquia, No. 20, 1822, p. 82).

En la temprana República adquirieron auge las denominadas Sociedades patrióticas, las cuales eran asociaciones de notables inspirados en el pensamiento republicano y con fuertes convicciones patrióticas. Allí participaron personas distinguidas y altos funcionarios cuyos objetivos era contribuir al desarrollo económico, pero también al fomento de la educación pública.

Esta sociabilidad se constituyó en un valioso apoyo al proyecto educativo oficial en vista de la debilidad económica e institucional de un Estado que se veía incapaz de cumplir las ambiciosas metas trazadas. A través de esas asociaciones se lograron valiosos aportes en la adecuación de escuelas, en la capacitación y pago de preceptores y en la donación de útiles escolares y material didáctico. De alguna manera, estos órganos voluntarios ayudaron a disminuir la presión ejercida sobre los cabildos, instancias que tenían la responsabilidad de organizar recolectas entre la comunidad (Clark, 2007, p. 58).

En Antioquia, fue el gobernador Francisco Urdaneta quien a través de un decreto firmado el 18 de marzo de 1822, dio vía libre para la creación de estas Sociedades de Amigos del País en cada cabecera de cantón. El primero de los propósitos de estos órganos debía ser la educación pública pero también tenían como metas paralelas promover la agricultura, el comercio, la industria y la minería. De esta forma, se crearon Sociedades en Medellín, Santa Fe de Antioquia, Santa Rosa, Rionegro y Marinilla.

Los miembros de la Sociedad conformada en Medellín tenían muy en claro sus prioridades pues creían "[...] que nada es tan necesario, nada tan importante a los progresos de la Joven Colombia en su carrera política como una educación esmerada en su juventud” (El Eco de Antioquia, No. 1, 1822, pp. 2). Tal motivación los animó a presentar en el mes de abril una propuesta concreta. Con miras a 
recoger los fondos para materializar este proyecto, plantearon al alto gobierno la posibilidad de que los 8.000 pesos de los fondos testamentarios dejados por el cura Juan Salvador de Villa, rector de la antigua escuela, se dedicaran al establecimiento de escuelas y colegios en vista de que aún no se había verificado el cumplimiento de las piadosas intenciones del testador a favor del convento de San Francisco y de la formación religiosa de dos sacerdotes oriundos de la provincia. La propuesta fue finalmente acogida por el gobierno.

Adicionalmente, la Sociedad informó que otros fondos recogidos con anterioridad habían pasado a ser manejados por el cabildo, a saber: 8.000 pesos dejados en la testamentaria de don Juan José Callejas, vecino de Medellín, para ser invertidos en la escuela y un aula de gramática; 4.000 pesos asignados por el finado don Gerónimo de Posada para el mismo fin y las limosnas que el presbítero Juan José Saldarriaga recolectó de casa en casa para destinarlas a fines educativos. Sin embargo, con suma preocupación la Sociedad denunció cómo muchos de estos haberes se habían menoscabado o perdido, razón por la cual sugirió al gobierno superior conformar una comisión que se encargara de averiguar en los libros capitulares las causas de este detrimento económico con el objeto de clarificar el estado actual de los fondos e identificar a los culpables. La misma Sociedad postuló al procurador Celedonio Trujillo, a José Antonio Benítez y a Pedro Facio Lince como candidatos a integrar esta comisión. El gobierno aprobó esta petición y la junta investigadora procedió a rendir informes semanales sobre el asunto (El Eco de Antioquia, No. 2, 1822, pp. 6-7).

Después de los grandes esfuerzos realizados para montar las escuelas, seguía una tarea aún más colosal y delicada: sostener los gastos de funcionamiento de estas instituciones. Las complicaciones económicas hicieron que muchos de estos establecimientos educativos fueran efímeros y otros de carácter intermitente.

En noviembre de 1821 el juez de Iguanacita, en jurisdicción de Medellín, solicitó al gobierno central se extinguiera la escuela de aquel partido y se agregara a la que existía en la cabecera municipal de Medellín. Esto en vista de la estrechez económica del vecindario que se sentía imposibilitado de seguir sosteniendo la institución. Escuchados estos argumentos, el 15 de febrero de 1822 el secretario del Interior José Manuel Restrepo dio su aprobación a esta propuesta (AGN, F. Instrucción Pública, t. 107, ff. 591v-619r).

\section{Maestros para el nuevo proyecto educativo}

La falta de educadores y la preocupación por sus calidades fueron dos desafíos importantes durante los primeros años de implementación de las escuelas públicas en tiempos republicanos. El ambiente de tensión militar que todavía se respiraba en algunos lugares se constituyó en un obstáculo para los planes de expansión del nuevo método de enseñanza.

La ley del 2 de agosto de 1821 había dispuesto que el gobernador de cada provincia era quien debía nombrar los maestros, para lo cual los cabildos o juntas especiales debían presentar una terna. Previamente, los candidatos serían examinados por una comisión de tres individuos nombrados por cada municipalidad (Actas, 1990, Vol. 2, p. 159). La ley del 18 de marzo de 1826 fue muy clara en señalar que los maestros de las escuelas debían ser de "conocida probidad y patriotismo", debiendo demostrar sus capacidades a través de un examen público y de una rigurosa "censura" (Codificación, 1924, t. VII, p. 402; Ley, 1826, pp. 2-19). 
El gobierno provincial de Antioquia reconoció en 1821 la dificultad para conseguir profesores de "medianos conocimientos" que quisieran vivir en parroquias y lugares apartados y con un escaso sueldo (AGN, F. Ministerio de Instrucción Pública, t. 107, f. 611r).

En este mismo año, el alcalde ordinario de primero voto de Santa Fe de Antioquia requirió del gobierno provincial permiso para que el impresor Manuel Antonio Balcázar fuera elegido como maestro de la escuela de esta ciudad por tener "cualidades necesarias" para tal función. Al final se dio vía libre a esta propuesta siempre y cuando no descuidara su trabajo de servicio al público y al gobierno (AHA, F. Gobernación de Antioquia, t. 122, f. 15r).

En Urrao había sido elegido Juan José Vidal pero fue incorporado al servicio de las armas, razón por la cual fue nombrado otro en su reemplazo. En la villa de Medellín hubo necesidad de buscar quién sustituyera al profesor Felipe Restrepo, tras haber este renunciado para seguir la vida sacerdotal (AHA, F. Gobernación de Antioquia, t. 122, ff. 18r-292r).

Pese a los controles estipulados en la ley, aún en 1823 el secretario del Interior se mostraba preocupado por la falta de docentes, problema que según él era resultado de la ignorancia en que habían estado sumidos los pueblos bajo el régimen de dominio hispánico. Él esperaba que con el tiempo y la buena gestión del gobierno republicano se difundieran las luces hasta el punto de que en la más remota de las parroquias existiera un ciudadano capaz de enseñar a los niños a leer, escribir y contar "con mediana perfección” (Restrepo, 1823, pp. 26-27). No obstante, ese era un propósito ambicioso que estaba muy lejos de las posibilidades reales del momento.

Si se registraban algunos tropiezos para ubicar maestros en las escuelas del método antiguo, mucho más arduo resultó el reto para conseguir preceptores que dominaran el nuevo sistema de enseñanza mutua.

Sin embargo, es importante reconocer que en cierta medida el nuevo método lancasteriano se constituyó en un alivio al déficit de maestros pues contemplaba la colaboración directa de los propios estudiantes en las labores de enseñanza a través de su función como monitores (García, 2007, p. 226).

Varios fueron los requisitos fijados por el gobierno para quienes querían acceder al cargo de maestros, exigencias que no se circunscribían únicamente a la capacidad académica, sino que también contemplaban otros aspectos como la solvencia moral de los aspirantes.

En el reglamento de escuelas expedido en la provincia el 28 de febrero de 1821, se dispuso que los maestros serían nombrados según la propuesta de los vecindarios y cabildos. Los individuos que ocuparan la terna debían presentar un examen que sería evaluado por una comisión de tres personas aptas para ello, nombradas por el cabildo o teniente de gobierno y con asistencia del síndico procurador general. Para comprobar que los maestros cumplieran cabalmente su función de enseñar, cada seis meses debían presentar un examen de las materias a dictar y, si no eran bien evaluados por la citada comisión, serían inmediatamente reemplazados (Reglamento, 1821, pp. 5-6).

A los pocos días, el gobernador nombró la comisión encargada de examinar a quienes serían designados preceptores en cada una de las localidades. Sobre Carmelo Tavares, el candidato a ocupar la vacante en la población de Sopetrán, los evaluadores constataron que era apto por sus "medianos" conocimientos de religión, aritmética y demás áreas de estudio estipuladas por el gobierno, pero se hizo énfasis en que su forma de letra era apenas legible. Sobre José Ramírez de la parroquia de San 
Jerónimo, se destacó el hecho de que escribía regularmente la letra "antigua" aunque sin mucho rigor en las normas de ortografía. Pero, lo más preocupante para los examinadores era que este candidato carecía de los principios básicos de enseñanza (AHA, F. Gobernación de Antioquia, t. 122, f. 40r).

Por no haberse encontrado una persona idónea en la parroquia de Santa Bárbara que se desempeñara como maestro, los vecinos propusieron como candidato a Gabino Soto, un niño que había sido criado por el cura. El gobernador aceptó esta solicitud, pero otorgó un plazo de seis meses para que este religioso lo instruyera suficientemente, al término de lo cual debía ser sometido a un riguroso examen para poder determinar si reunía todos los requisitos académicos para ser nombrado como maestro del lugar (AHA, F. Gobernación de Antioquia, t. 122, f. 75r).

Los procesos de selección de maestros no estuvieron exentos de controversias e irregularidades ya fuera porque no se surtía la totalidad de los trámites formalizados por la ley o porque emergían posturas encontradas sobre las calidades académicas y morales de los candidatos.

En 1821 en la parroquia de San Jerónimo fue nombrado inicialmente como maestro José Ramírez, aunque fue necesario reemplazarlo por Cipriano Mosquera por haberse hecho aquella primera designación sin la anuencia del vecindario (AHG, F. Gobernación de Antioquia, t. 122, f. 18r).

La remuneración de los maestros no era un asunto meramente económico, sino que también estaba íntimamente ligado al ámbito de la calidad educativa. Ya el vicepresidente Santander había advertido que, entre mayor fuera el sueldo, mejor debía ser el desempeño del educador. Según el decreto dictado por este alto funcionario en 1820, los gobernadores debían asignar los sueldos de los profesores según la disponibilidad de sobrantes de las rentas de propios, una vez satisfechos los gastos ordinarios (Osorio, 1969, p. 154).

En estos primeros meses de gobierno republicano, cuando aún no se habían diseñado reglas claras sobre la remuneración a los maestros, se recurrió a un abanico de opciones y de fuentes de financiación privadas y públicas, ya fuera del orden nacional, provincial y local, según el contexto vivido en cada espacio territorial.

En vista de las dificultades económicas para pagar a los maestros los 200 pesos que había dispuesto el decreto del 6 de octubre de 1820, las autoridades regionales debieron pensar en cómo reacomodaban esta disposición a las realidades económicas de sus territorios, obviamente con el previo aval del gobierno central. Eso fue precisamente lo que hizo el gobernador de Antioquia José Manuel Restrepo, quien decidió a finales de enero de 1821 establecer una categorización en las escuelas. Aquellas denominadas de primer orden correspondían a las ciudades y villas, en cuyo caso los maestros recibirían de 200 a 300 pesos. Entre tanto, en las parroquias, en los lugares apartados y en los pueblos de indios, denominados como de segunda categoría, a los maestros se les pagarían menos de 200 pesos, según la capacidad económica del vecindario (AGN, F. Instrucción Pública, t. 107, f. 615r).

En el marco de la discusión registrada en el Congreso de Cúcuta de 1821, el dirigente antioqueño José Manuel Restrepo pensaba que muchas parroquias no estaban en capacidad financiera ni siquiera para reunir 100 pesos y por ello creía que lo importante era que el mayor número de poblados contaran con estos establecimientos educativos, así fuera "[...] de cualquier modo, pues cuando los maestros no puedan enseñar a escribir, bastará que enseñen a leer, porque es mil veces peor que los niños no aprendan nada" (Actas, 1990, Vol. 2, p. 49). 
Después de evaluada esta y otras propuestas planteadas por los congresistas reunidos en Cúcuta, finalmente quedó consagrado en la ley que el sueldo de los maestros sería asignado por los gobernadores y debía ser proporcional a la cantidad de habitantes y riqueza de cada población (Actas, 1990, Vol. 2, p. 159).

En reiteradas ocasiones, los profesores clamaban porque se les colaborara con los gastos de alojamiento sin que esto afectara sus bolsillos. Al ser elegido en 1821 Manuel Antonio Balcázar como maestro de escuela de la ciudad de Santa Fe de Antioquia, pidió que en vista de su precaria situación económica y la corta asignación del sueldo, se consiguiera como sede una casa grande y cómoda en la cual él pudiera fijar su residencia (AHA, F. Gobernación de Antioquia, t. 122, f. 21r).

A principios de este mismo año los vecinos de Sopetrán preguntaron al gobernador cómo se podía resolver el problema de vivienda para Carmelo Tavares, el maestro designado para la escuela de dicha localidad, por cuanto él debía arrendar una casa y eso repercutiría en detrimento de los 240 pesos asignados como salario. En este caso, se respondió recordando la directiva del gobierno central que había dictaminado que el alojamiento lo debía asumir cada profesor de su propio peculio (AHA, F. Gobernación de Antioquia, t. 122, f. 39r).

La falta de pagos oportunos llegó a generar bastante inconformismo en los maestros y con frecuencia provocaba una parálisis en las actividades curriculares. Ambrosio Restrepo, preceptor del pueblo de Guayabal, se quejaba en 1821 de cómo en dos meses y medio que llevaba al frente de la escuela aún no había recibido ni un maravedí por más solicitudes y ruegos hechos al alcalde partidario para que realizara la recolecta en el vecindario. Restrepo se declaró desconcertado al no recibir el incentivo económico por sus esmerados esfuerzos que le habían valido el público reconocimiento. Pidió afanosamente ayuda por su condición de pobre y por tener una considerable familia que debía alimentar. Estas demoras las atribuía el profesor a la apatía generalizada de muchos de los funcionarios locales pues ni siquiera habían asistido ni promocionado el certamen académico realizado en dicho plantel educativo (AHA, F. Gobernación de Antioquia, t. 122, f. 63r).

\section{El trato a los alumnos y la dotación de útiles escolares}

Las nuevas reglas y métodos de estudio suscitaron también cambios en las relaciones entabladas por los profesores con sus alumnos y con los padres de familia. No fue extraño encontrar reacciones conservadoras a las innovaciones de carácter educativo.

En cuanto al trato del maestro hacia sus estudiantes, las tempranas normas republicanas abogaron por flexibilizar los fuertes castigos físicos que habitualmente se utilizaban en tiempos coloniales. De manera simultánea, se fijaron algunos incentivos para aquellos que demostraran buen comportamiento.

En los numerales $9^{\circ}$ y $10^{\circ}$ del reglamento diseñado a principios de diciembre de 1819 para las escuelas de la provincia de Antioquia, se establecieron como premisas la tranquilidad, la moderación, la paciencia y la razón por encima del tono ofensivo:

Artículo $9^{\circ}$. Evitará igualmente la severidad demasiada y la excesiva indulgencia. No castigará al niño con pasión, cólera ni alteración en semblante y palabras, de modo que entienda y quede convencido que se castiga por necesidad y no por capricho, porque éste siempre irrita y nunca corrige. Las reprensiones y 
castigos no han de ser ni demasiado largos ni demasiado frecuentes, de modo que quiten a los niños la esperanza de poder enmendarse.

Artículo $10^{\circ}$. Evitará también el castigo de azotes, que ofende la modestia y tiene mucho de indecente y bajo; subrogando otros, como el de la palmeta, privación de ciertas diversiones y asuetos; encierro por algunas horas, reprensión a vista de sus iguales, y otros semejantes que dicte la prudencia y el deseo de su enmienda. Pero en las clases de primeras letras y gramática, podrán castigarse con azotes que no pasen de seis, el irrespeto a sus maestros, las pendencias y palabras indecentes con sus compañeros, y algunas otras faltas notables contra la decencia y la moral cristiana, a fin de que la singularidad del castigo inspire horror a estos defectos (Martínez, 2011, p. 372).

Además de adecuar la sede de la escuela y costear el pago del maestro, debían adelantarse las gestiones con miras a la consecución de textos, útiles escolares y demás elementos básicos para la dotación del aula de clases. El gobierno central trató en lo posible de efectuar algunas dotaciones pero la mayoría de las veces esa era una responsabilidad de las autoridades locales y de las comunidades.

Vale tener en cuenta que las escuelas de enseñanza mutua requerían de una mayor inversión en su dotación por cuanto su método implicaba el uso de una buena cantidad de elementos pedagógicos que no eran utilizados en el método antiguo. La situación resultaba aún más complicada por cuanto algunos de estos elementos eran importados.

A principios de 1823, el gobierno provincial giró recursos al señor Juan Pablo Sañudo para que en su viaje a Jamaica adquiriera 200 pizarras, 250 lapiceros, 80 lápices, 25 tinteros y 2 pitos a fin de completar la dotación de la recién estrenada escuela lancasteriana de la villa de Medellín (El Eco de Antioquia, No. 35, 1823, p. 143; El Eco de Antioquia, No. 36, 1823, p. 148).

Corría el mes de julio de 1826 cuando fue fundada una escuela lancasteriana en la parroquia de San Vicente. La construcción de la casa fue estimada en 1.300 pesos y esta era su dotación: un estrado de una vara y cuatro de alto para el preceptor, una mesa y una silla de madera sobre el estrado, una mesa para el monitor general, 14 mesas con pequeños cajoncillos a la derecha para guardar lápices, 14 asientos de madera asegurados al suelo con vigas labradas, 6 telégrafos, un tablero grande de forma circular sostenido con un armazón de madera para operaciones de aritmética, un tablero largo con el alfabeto en letras mayúsculas cursivas por un lado y por el otro el de minúsculas, 72 tablillas de madera fijadas en el mismo entorno del salón con igual número de planillas impresas con frases alusivas a máximas morales y políticas, 60 pizarras de madera aseguradas en marcos de madera, 1.000 lápices de piedra y 12 tarritos de loza para tinteros (AGN, F. Instrucción Pública, t. 107, ff. 727r-729v).

No hay duda de que el fomento de la educación pública en tiempos republicanos trajo consigo un impulso a la producción de libros y materiales didácticos después de una larga etapa de estancamiento vivida por cuenta de las guerras de Independencia. Desde luego, ese auge de publicaciones estaba ligado al aumento en el número de imprentas.

En el reglamento para las escuelas de primeras letras de la provincia de Antioquia publicado en febrero de 1821, se instó a los maestros para que siguieran el manual titulado Reglas para enseñar a leery escribir, en el cual se enseñaba la "bella forma" de letra llamada de Morante, conforme a los principios de Palomares. Era obligación de los educandos aprender de memoria los dogmas de la religión a través del catecismo de Astete añadido, el Catecismo de Fleuri o el Catecismo de Pouget. Para la moral se recomendó el uso de la Escuela de Señoritas y el Telémaco. En cuanto a la aritmética se recomendó cualquiera de los 
manuales que en ese momento circulaban mientras el gobierno hacía imprimir uno para el uso de las escuelas de la provincia así como también sería publicado un compendio de los derechos del hombre en sociedad y de los deberes del ciudadano en Colombia, con las bases del buen gobierno.

Las rentas de propios en las cabeceras de cantón o, los vecinos para el caso de las parroquias, tendrían la obligación de proporcionar un silabario de letras grandes sobre tablitas o cartones y "un lienzo o tablero dado al óleo para enseñar la aritmética con el yeso necesario para hacer los números" (AGN, F. Instrucción Pública, t. 107, f. 614D).

En el mes de abril se imprimió el Método o reglas para enseñar a leer y escribir a los niños. Este manual fue redactado por el gobernador de Antioquia José Manuel Restrepo con base en varios autores y para ser repartido en las escuelas de la provincia. El objetivo era que los niños contaran con un texto en el que pudieran estudiar con facilidad. El impreso contenía un apéndice con los derechos y deberes del hombre y los principios elementales del gobierno republicano para formar "buenos ciudadanos". Este era, según Restrepo, un primer esfuerzo con la esperanza de estimular a otros estudiosos y letrados a perfeccionar y complementar a futuro esta obra (AGN, F. Instrucción Pública, t. 107, f. 612r).

El Catecismo de Abad Fleuri fue puesto en venta a mediados de octubre de 1822 en la villa de Medellín a través de la prensa local. Podía adquirirse en la tienda del señor Nicolás Suárez a 8 pesos en rústica (El Eco de Antioquia, No. 22, 1822, p. 92).

Pese a estos avances en materia de circulación, en un informe presentado en abril de 1823, el gobierno central reconoció que todavía escaseaban los libros para esta primera etapa de enseñanza pero se esperaba que aumentaran las imprentas para así multiplicar las ediciones (Restrepo, 1823, p. 26).

\section{Conclusiones}

Sin duda, lo que más vale destacar de este estudio fue el liderazgo de la provincia de Antioquia en el marco del proyecto educativo planteado por el gobierno republicano. Aún en medio de los estragos de las guerras de Independencia y de la crisis económica, fue evidente la solidaridad de la comunidad y el esfuerzo de las instancias de gobierno provincial y local por fomentar la instalación de escuelas públicas en este territorio. Las reglamentaciones promulgadas en este marco espacial fueron un punto de referencia y sirvieron de complemento a las normas dictadas a nivel nacional en el intento por organizar el sistema educativo.

De alguna manera, este temprano impulso a la educación básica le permitiría a esta provincia recuperar paulatinamente su protagonismo económico y sería un factor de progreso que marcaría la diferencia con otras zonas del país.

El creciente número de jóvenes egresados de estos planteles encontraría a partir de 1822, con la fundación del Colegio de Antioquia (Eco de Antioquia, No. 27, 1822, p. 112), un espacio propicio para avanzar en la escala de formación educativa, con lo cual se dieron pasos importantes en la consolidación de una sociedad letrada permeada por los principios republicanos y el sentimiento de Patria en torno a la formación de ciudadanos. 
En las décadas siguientes del siglo XIX, a pesar del impacto generado por las guerras civiles, el número de establecimientos educativos siguió en aumento. Así por ejemplo, en 1835 existían en la provincia 79 planteles mientras que para 1888 se contabilizaban 256 (Londoño, 2012, p. 50).

No obstante, hay que reconocer también que no fueron tan alentadores los progresos para las niñas y para sectores marginados de la sociedad como los indígenas y las comunidades negras (Pita, 2014), las cuales debieron afrontar mayores dificultades para acceder a estos niveles básicos de educación.

\section{Referencias bibliográficas}

Actas del Congreso de Cúcuta 1821. (1990). Bogotá: Biblioteca de la Presidencia de la República, Vol. II. Ahern, E. (1991). "El desarrollo de la educación en Colombia: 1820-1850". Revista Colombiana de Educación, (22-23), pp. 5-88.

Archivo General de la Nación (AGN), Bogotá-Colombia. Sección República, Fondo Ministerio de Instrucción Pública.

Archivo Histórico de Antioquia (AHA), Medellín-Colombia. Fondo Gobernación de Antioquia.

Clark, M. L. (2007). "Conflictos entre el Estado y las élites locales sobre la educación colombiana durante las décadas de 1820 y 1830". Historia Crítica, (34), pp. 32-61.

Codificación Nacional de todas las leyes de Colombia desde el año de 1821. (1924). Bogotá: Imprenta Nacional, tomo VII.

Constitución del Estado de Antioquia. (1812). Santafé de Bogotá: En la Imprenta de D. Bruno Espinosa.

Correo de la ciudad de Bogotá, Bogotá, Imprenta de Nicomedes Lora, 1821.

Gaceta de Colombia, Bogotá, Imprenta de Espinosa, 1825.

García Sánchez, B. Y. (2007). De la educación doméstica a la educación pública en Colombia. Transiciones de la Colonia a la República. Bogotá: Universidad Distrital Francisco José de Caldas.

Gazeta Ministerial de la República de Antioquia, Medellín, Imprenta del Estado por el ciudadano Manuel María Viller-Calderón, 1814.

Ley Fundamental de la República de Colombia. (1819). Bogotá: [s.n.].

Ley y reglamentos orgánicos de la enseñanza pública en Colombia acordados en el año de 1826. (1826). Bogotá: En la Imprenta de Manuel María Viller-Calderon.

Londoño Vega, P. \& Londoño Vélez, S. (2012). Los niños que fuimos. Huellas de la infancia en Colombia. Bogotá: Banco de la República.

López Domínguez, L. H. (comp.). (1990). Obra educativa de Santander 1819-1826. Bogotá: Biblioteca de la Presidencia de la República, Vol. I.

Manual del sistema de enseñanza mutua aplicado a las escuelas primarias de los niños. (1826). Bogotá: Impreso por S. S. Fox.

Martínez Boom, A. (2011). Memorias de la escuela pública. Bucaramanga: Universidad Industrial de Santander.

Mier, J. (1983). La Gran Colombia. Bogotá: Presidencia de la República, 1983, tomo 1.

Ocampo López, J. (2012). "Las reformas educativas en la Primera República Granadina (1810-1816)”, en: Ocampo López, J. \& Soler Lizarazo, C. Reformismo en la educación colombiana. Historia de las politicas educativas 1770-1840. Bogotá: Instituto para la Investigación Educativa y el Desarrollo Pedagógico, pp. 81-95. 
Ocampo López, J. (1987). Santander y la educación. Ideario educativo del "Hombre de las Leyes" y su influencia en los colegios santanderinos. Tunja: Colegio de Boyacá.

Osorio Racines, F. (1969). Decretos del General Santander. 1819-1821. Bogotá: Universidad Nacional.

Osorio, A. \& Vergara, E. (1821). Los encargados de la Secretaría General del Departamento de Cundinamarca presentan a S. E. el General F. de P. Santander, vicepresidente del mismo Departamento, la memoria correspondiente al año de 1820. Bogotá: Imprenta de Espinosa.

Pita Pico, R. (2016). Celebraciones políticas y militares en Colombia: de virreyes y monarcas al santoral de la patria. Bogotá: Academia Colombiana de Historia.

Pita Pico, R. (2014). "La exclusión étnica en la educación básica y secundaria en la naciente República de Colombia, 1819-1825”. Revista Historia de la Educación Colombiana, (17) 17, pp. 79-100.

Reglamento para el uso y gobierno de las escuelas de la provincia de Antioquia. (1821). Impreso tomado de: AGN, Sección República, Fondo Ministerio de Instrucción Pública, tomo 107, ff. 614A-614F.

Restrepo, J. M. (1823). Memoria que el secretario de Estado y del despacho del Interior presentó al Congreso de Colombia sobre los negocios de su Departamento. Bogotá: Imprenta de Espinosa.

Restrepo, J. M. (1826). Exposición que el Secretario de Estado del Despacho del Interior de la República de Colombia hiro al Congreso de 1826 sobre los negocios de su Departamento. Bogotá: Imprenta Manuel M. Viller-Calderón.

Safford, F. (1989). El ideal de lo práctico. El desafío de formar una elite técnica y empresarial en Colombia. Bogotá: Universidad Nacional-El Áncora Editores. 